\title{
Analytical Study of the Confining Medium Diameter Impact on Load-Carrying Capacity of Rock Bolts
}

\author{
Jianhang Chen $\mathbb{D},{ }^{1,2}$ Xin Dai $\mathbb{D},{ }^{1}$ and Junwen Zhang $\mathbb{D}^{1}$ \\ ${ }^{1}$ School of Energy and Mining Engineering, China University of Mining and Technology (Beijing), Beijing 100083, China \\ ${ }^{2}$ International Joint Research Laboratory of Henan Province for Underground Space Development and Disaster Prevention, \\ Henan Polytechnic University, Jiaozuo 454003, China
}

Correspondence should be addressed to Junwen Zhang; zhangjunwen1977@163.com

Received 4 November 2020; Revised 22 March 2021; Accepted 16 April 2021; Published 24 April 2021

Academic Editor: Ivan Giorgio

Copyright (c) 2021 Jianhang Chen et al. This is an open access article distributed under the Creative Commons Attribution License, which permits unrestricted use, distribution, and reproduction in any medium, provided the original work is properly cited.

The force transfer of fully grouted rock bolts is playing a significant effect in determining the rock reinforcement quality. To evaluate the performance of rock bolts, laboratory pulling tests were commonly used. Experimental tests proved that the confining medium diameter had an effect on the rock bolting performance. However, little analytical work has been performed to investigate the impact of the confining medium diameter on rock bolt load-carrying capacity. Therefore, this paper analytically studied the confining medium diameter effect on the load-carrying capacity of rock bolts. It was found that the load-carrying capacity of rock bolts was obviously affected by the confining medium diameter. Moreover, the larger the confining medium diameter, the higher the load-carrying capacity of rock bolts. However, the ascending rate of the load-carrying capacity gradually declined. This loadcarrying capacity variation trend consistently agreed with experimental results. Moreover, with the confining medium diameter ascending, the load-carrying capacity variation trend was consistent when the confining medium modulus was under different levels. Last, it was found that, with the confining medium modulus ascending, the critical influence diameter gradually dropped.

\section{Introduction}

Rock bolts are tendons or cables that are commonly used in mining engineering and civil engineering to reinforce excavated rock masses or soils $[1,2]$. Numerous in situ tests proved that rock bolts are efficient in improving the internal strength of the surrounding confining medium, namely, rock masses and soils [3]. Therefore, rock bolts are becoming more significant in maintaining the stability of underground roadways, chambers, tunnels, surface slopes [4], and rooms in the room and pillar mining [5]. In the fully grouted rock bolting system, the bolt can deform consistently with the confining medium $[6,7]$. Then, the bolt tendon can interact with the confining medium to transfer the force $[8,9]$.

To investigate the load-carrying capacity of rock bolts, laboratory pulling tests were the most widely preferred method [10]. Specifically, a natural or artificial rock block can be prepared as the confining medium. Then, the bolt was installed in the drilled hole in the rock block. Cement-based or resin grout was poured into the drilled hole to bond the bolt and rock block. After the grout in the bolting hole fully cured, the bolt was pulled out from the rock block. During the experiment, load cell and displacement transducers were adopted to monitor the pulling force and displacement. With the recorded data, the force-displacement relationship of rock bolts can be plotted, representing the performance of rock bolts. For example, Skrzypkowski et al. [11] considered that the load-carrying capacity of segmentally installed rock bolts can be influenced by the bolting hole diameter. To investigate this impact, they conducted pulling tests on rock bolts with a diameter of $24 \mathrm{~mm}$. Four different bolting hole diameters were used, ranging from $28 \mathrm{~mm}$ to $37 \mathrm{~mm}$. The results showed that, at the certain installing length of $100 \mathrm{~mm}$ and $200 \mathrm{~mm}$, the maximum load-carrying capacity of rock bolts varied with the bolting hole diameter. Moreover, it was concluded that the optimum load-carrying capacity appeared when the bolting hole diameter was $32 \mathrm{~mm}$ 
Previous research work showed that, in the laboratory tests, the geometry of the rock block was different. Usually, researchers would like to prefer cylindrical or cubic rock blocks. However, it was more common to use cylindrical rock blocks $[12,13]$. It is interesting to see that although researchers used this method to study the performance of rock bolts, the diameter of rock blocks was largely different. For laboratory tests, the diameter of rock blocks usually ranged from $100 \mathrm{~mm}$ to $500 \mathrm{~mm}$ [14]. Previous researchers conducted a number of tests to reveal the loading performance of rock bolts when the condition of the bolt, grout, and rock masses varied [15-17]. However, less attention was paid to evaluate the confining medium diameter effect on load-carrying capacity of rock bolts.

Rajaie [18] was the pioneer to study the confining medium diameter effect. Moreover, he used concrete materials to cast cylindrical samples. Five different sample diameters were used: $100 \mathrm{~mm}, 150 \mathrm{~mm}, 200 \mathrm{~mm}, 250 \mathrm{~mm}$, and $300 \mathrm{~mm}$. The results showed that when the confining medium diameter was small, the peak force of rock bolts ascended rapidly with the confining medium diameter ascending. However, it almost stopped ascending once the diameter was beyond $200 \mathrm{~mm}$. This indicated that there was a critical influence diameter (CID). Once the rock block diameter was larger than this CID, further ascending the rock block diameter had marginal effect on the performance of rock bolts. Chen et al. [19] continued this experimental work, finding that the boundary condition had an effect in determining the CID.

Although numerous analytical models were proposed to study the performance of rock bolts [20-24], and little work has been focused on the confining medium diameter effect. Therefore, this paper conducted an analytical study to investigate the influence of the confining medium diameter on the load-carrying capacity of rock bolts. First, the analytical model concept was illustrated. Then, the confining medium diameter effect was studied with this analytical model and the results were compared with experimental results. Last, the influence of the confining medium modulus on the CID was analysed.

\section{Analytical Modelling Approach}

The authors of this paper previously deduced an analytical model to study the loading performance of rock bolts [25]. Specifically, after the rock bolt was loaded, shearing stress occurred at the bonding face between the tendon and grout. Moreover, shearing stress occurred at the bonding face between the grout and confining medium, as shown in Figure 1.

Then, a trilinear formula was used to illustrate the coupling and decoupling behaviour of the bonding face [26]:

$$
\begin{aligned}
& \tau=\frac{\tau_{1}}{s_{1}} s\left(0 \leq s \leq s_{1}\right), \\
& \tau=\frac{\tau_{1} s_{2}-\tau_{2} s_{1}}{s_{2}-s_{1}}-\frac{\tau_{1}-\tau_{2}}{s_{2}-s_{1}} s\left(s_{1}<s \leq s_{2}\right),
\end{aligned}
$$

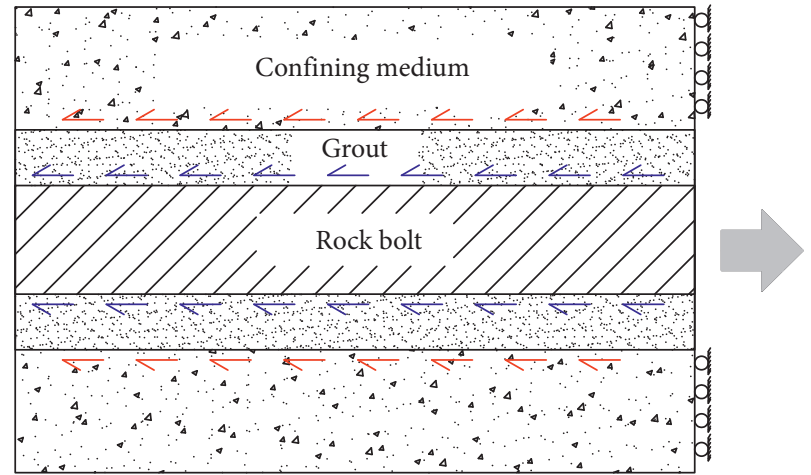

FIGURE 1: State of the bolting system after the bolt was loaded.

$$
\tau=\tau_{2}\left(s>s_{2}\right),
$$

where $\tau$ is shearing stress at the bonding face between the tendon and grout, $\tau_{1}$ is shearing strength, $\tau_{2}$ is residual shearing strength, $s$ is slipping between the tendon and grout, $s_{1}$ is slipping when $\tau_{1}$ was reached, and $s_{2}$ is slipping when $\tau_{2}$ was reached.

Then, through analysing the equilibrium relationship between the tensile stress in the tendon and shearing stress at the bonding face, the governing equation for the bolting system was obtained [25]:

$$
\begin{aligned}
\frac{d^{2} s(x)}{d x^{2}}-\lambda^{2} \tau(x) & =0, \\
\lambda^{2} & =\frac{4}{D_{\mathrm{b}}}\left(\frac{1}{E_{\mathrm{b}}}+\frac{A_{\mathrm{b}}}{E_{\mathrm{m}} A_{\mathrm{m}}}\right),
\end{aligned}
$$

where $D_{\mathrm{b}}$ is tendon diameter, $E_{\mathrm{b}}$ is elastic modulus of the tendon, $A_{\mathrm{b}}$ : cross-section area of the tendon, $E_{\mathrm{m}}$ is elastic modulus of the confining medium, and $A_{\mathrm{m}}$ is the crosssection area of the confining medium.

The whole pulling process of rock bolts was divided into five different phases, including the elastic phase (I), the elastic-softening phase (II), the elastic-softening-debonding phase (III), the softening-debonding phase (IV), and the debonding phase $(\mathrm{V})$ [27]. Through substituting the trilinear formula and boundary condition in each phase into Equation (2), the relationship between the pulling force and displacement can be obtained.

Specifically, in Phase I, the pulling force and displacement can be computed as

$$
\begin{aligned}
P & =\frac{\pi D_{\mathrm{b}} \tau_{1} \tanh \left(\lambda_{1} L\right)}{\lambda_{1} s_{1}} u, \\
\lambda_{1}^{2} & =\frac{\tau_{1}}{s_{1}} \lambda^{2},
\end{aligned}
$$

where $P$ is pulling force, $L$ is grouted length, and $u$ is pulling displacement.

In Phase II, the pulling force and displacement can be computed as 


$$
\begin{aligned}
& u=\frac{\lambda_{1} s_{1}}{\lambda_{2}} \tan \mathrm{h}\left(\lambda_{1}\left(L-a_{\mathrm{s}}\right)\right) \sin \left(\lambda_{2} a_{\mathrm{s}}\right)-\frac{\lambda_{1}^{2} s_{1}}{\lambda_{2}^{2}} \cos \left(\lambda_{2} a_{s}\right)+\frac{\tau_{1} s_{2}-\tau_{2} s_{1}}{\tau_{1}-\tau_{2}}, \\
& P=\pi D_{\mathrm{b}} \tau_{1}\left(\frac{1}{\lambda_{1}} \tan \mathrm{h}\left(\lambda_{1}\left(L-a_{\mathrm{s}}\right)\right) \cos \left(\lambda_{2} a_{\mathrm{s}}\right)+\frac{1}{\lambda_{2}} \sin \left(\lambda_{2} a_{\mathrm{s}}\right)\right), \\
& \lambda_{2}^{2}=\frac{\tau_{1}-\tau_{2}}{s_{2}-s_{1}} \lambda^{2}
\end{aligned}
$$

where $a_{\mathrm{s}}$ is the softening length.

In Phase III, the pulling force and displacement can be computed as

$$
\begin{aligned}
& u=s_{\mathrm{r}}+\frac{\lambda^{2} a_{\mathrm{d}}^{2} \tau_{2}}{2}+\left(\frac{\tau_{1} \lambda^{2}}{\lambda_{1}} \tanh \left(\lambda_{1}\left(L-a_{\mathrm{d}}-a_{\mathrm{s}}\right)\right) \cos \left(\lambda_{2} a_{\mathrm{s}}\right)+\frac{\tau_{1} \lambda^{2}}{\lambda_{2}} \sin \left(\lambda_{2} a_{\mathrm{s}}\right)\right) a_{\mathrm{d}}, \\
& P=\pi D_{\mathrm{b}}\left(\frac{\tau_{1}}{\lambda_{1}} \tanh \left(\lambda_{1}\left(L-a_{\mathrm{d}}-a_{\mathrm{s}}\right)\right) \cos \left(\lambda_{2} a_{\mathrm{s}}\right)+\frac{\tau_{1}}{\lambda_{2}} \sin \left(\lambda_{2} a_{\mathrm{s}}\right)+\tau_{2} a_{\mathrm{d}}\right),
\end{aligned}
$$

where $a_{\mathrm{d}}$ is the debonding length.

In Phase IV, the pulling force and displacement can be computed as

$$
\begin{aligned}
& u=s_{2}+\lambda^{2} \tau_{2} a_{\mathrm{d}}\left(\frac{a_{\mathrm{d}}}{2}+\frac{\tan \left(\lambda_{2}\left(L-a_{\mathrm{d}}\right)\right)}{\lambda_{2}}\right), \\
& P=\pi D_{\mathrm{b}} \tau_{2}\left(\frac{\tan \left(\lambda_{2}\left(L-a_{\mathrm{d}}\right)\right)}{\lambda_{2}}+a_{\mathrm{d}}\right) .
\end{aligned}
$$

Last, in Phase V, the pulling force and displacement can be computed as

$$
P=\pi D_{\mathrm{b}} \tau_{2}\left(L+s_{2}+\frac{\lambda^{2} \tau_{2} L^{2}}{2}-u\right)
$$

Equations (4)-(13) contributed to the force-displacement relationship of rock bolts. Moreover, a good agreement was obtained between the model and physical test data [25].

\section{Modelling Process and Results}

To investigate the effect of the confining medium diameter on the load-carrying capacity of rock bolts, analytical tests were performed. Specifically, it was assumed that pulling tests were conducted on deformed rock bolts with the diameter of $25 \mathrm{~mm}$ and elastic modulus of $200 \mathrm{GPa}$. It was admitted that the deformed rock bolts had ribs on the tendon surface. Moreover, the mechanical parameters of ribs, namely, rib height and rib spacing may be dependent on the bolt type [28, 29]. However, for this paper, at the current stage, there was no specific evaluation on the rib height and rib spacing. It was assumed that, after the tendon was loaded, the deformed rock bolt induced shearing stress at the bonding face between the tendon and grout. As for the influence of the rib height and rib spacing on the shearing stress at the bonding face between the tendon and grout, further work will be continued.

The bolt was installed in the bolting hole with a diameter of $40 \mathrm{~mm}$ and grouted length of $2 \mathrm{~m}$. For the grout, it was assumed that it had an unconfined compressive strength of $50 \mathrm{MPa}$. For the confining medium, it was assumed that it had an elastic modulus of $20 \mathrm{GPa}$ and unconfined compressive strength of $30 \mathrm{MPa}$. For the bonding face between the tendon and grout, the bonding-slipping data tabulated in Table 1 were used.

Table 1 summarised the mechanical properties of the bonding face between the tendon and grout: shearing strength $\left(\tau_{1}\right)$, slipping where shearing strength reached $\left(s_{1}\right)$, residual shearing strength $\left(\tau_{2}\right)$, and slipping where residual shearing strength reached $\left(s_{2}\right)$. They can be computed with the following equation [30]:

$$
\tau=\frac{P}{\pi D_{\mathrm{b}} L} .
$$

Specifically, previous research revealed that if the grouted length of the rock bolt was short enough, the shearing stress at the bonding face can be treated uniform [14]. Therefore, after conducting pulling tests on rock bolts with short grouted length, the maximum pulling force and residual pulling force can be substituted into Equation (14) to compute the shearing strength $\left(\tau_{1}\right)$ and residual shearing strength $\left(\tau_{2}\right)$. Then, the slipping where shearing strength reached $\left(s_{1}\right)$ equalled the pulling displacement where the maximum pulling force occurred. The slipping where residual shearing strength reached $\left(\tau_{2}\right)$ equalled the pulling displacement where the residual pulling force occurred.

In this paper, for the diameter of the confining medium, four different values were used: $100 \mathrm{~mm}, 150 \mathrm{~mm}, 200 \mathrm{~mm}$, and $250 \mathrm{~mm}$. The configuration of this analytical pulling test is shown in Figure 2. This analytical pulling process was generally consistent with the traditional pulling experiment 
TABLE 1: Bonding-slipping data for the bonding face between the tendon and grout.

\begin{tabular}{lccc}
\hline$\tau_{1}(\mathrm{MPa})$ & $s_{1}(\mathrm{~mm})$ & $\tau_{2}(\mathrm{MPa})$ & $s_{2}(\mathrm{~mm})$ \\
\hline 2 & 1 & 1 & 3 \\
\hline
\end{tabular}

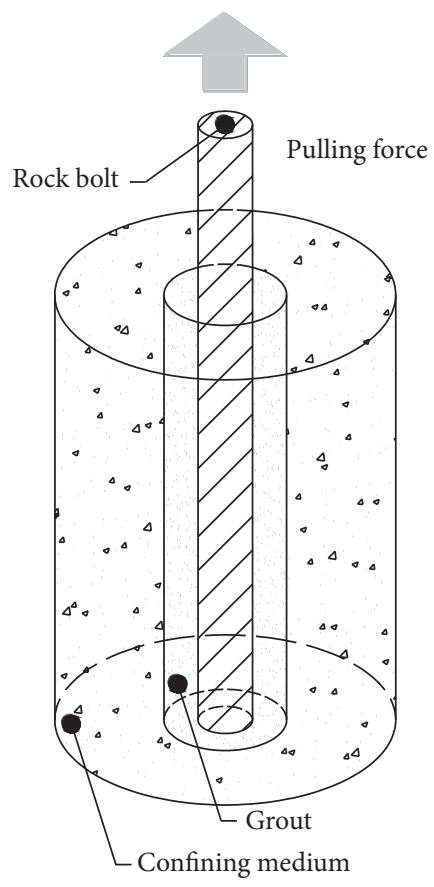

Figure 2: Configuration of the rock bolt loading system.

of rock bolts [31], where the tendon was pulled with a loading rate of $1 \mathrm{~mm} / \mathrm{min}$ and the load cell together with the linear variable differential transformer were used to measure the pulling force and displacement respectively.

Then, the analytical pulling tests were performed and the results are shown in Figure 3. Apparently, the confining medium diameter had an effect in determining the performance of rock bolts. Specifically, there was a positive relationship between the load-carrying capacity of rock bolts and the confining medium diameter. Moreover, the ascending rate of the peak force had a tendency to decline. For example, when the confining medium diameter ranged from $200 \mathrm{~mm}$ to $250 \mathrm{~mm}$, the peak force of rock bolts was quite close.

To further investigate the influence of the confining medium diameter on the performance of rock bolts, a series of pulling tests was conducted. In this computation, the confining medium diameter varied in the domain $(50 \mathrm{~mm}$, $1000 \mathrm{~mm}$ ). Then, the variation trend of the bolt peak force, when the confining medium diameter was varying, was computed, as shown in Figure 4. The peak force ascended significantly when the confining medium diameter varied from $50 \mathrm{~mm}$ to $300 \mathrm{~mm}$. However, when the confining medium diameter was larger than $300 \mathrm{~mm}$, the ascending rate of the peak force became gentle. Moreover, when the diameter was beyond $400 \mathrm{~mm}$, the peak force became almost constant.
To confirm the accuracy of the analytical modelling results, the experimental tests performed by Rajaie [18] were used as a comparison, as shown in Figure 5. It can be seen that the peak force variation trend in analytical modelling generally agreed well with the experimental test trend. In experimental tests, the peak force rose rapidly with the confining medium diameter when it was smaller than $200 \mathrm{~mm}$. After it was beyond $250 \mathrm{~mm}$, the peak force became almost unchangeable. This variation trend was successfully reflected in analytical modelling.

In the above analysis, the elastic modulus of the confining medium was set as $20 \mathrm{GPa}$. However, in experimental tests, the material with a different modulus can be used to cast the confining medium. Therefore, further pulling tests were performed with different confining medium moduli $\left(E_{\mathrm{m}}\right)$. Specifically, three different moduli were used: $1 \mathrm{GPa}$, $5 \mathrm{GPa}$, and $20 \mathrm{GPa}$. The peak force variation trend results are shown in Figure 6. Apparently, the peak force variation trend was consistent. This indicated that although the confining medium modulus was different, there was a CID. The confining medium had little effect on the peak force once its diameter was over than the CID. It was also found that when the confining medium modulus was different, the CID was also different. For example, when the confining medium modulus was $20 \mathrm{GPa}$, the peak force became almost constant when the confining medium diameter was larger than $400 \mathrm{~mm}$. Nevertheless, this value was changed when the 


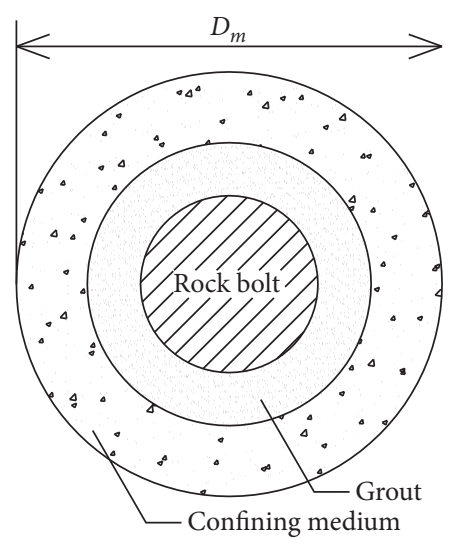

(a)

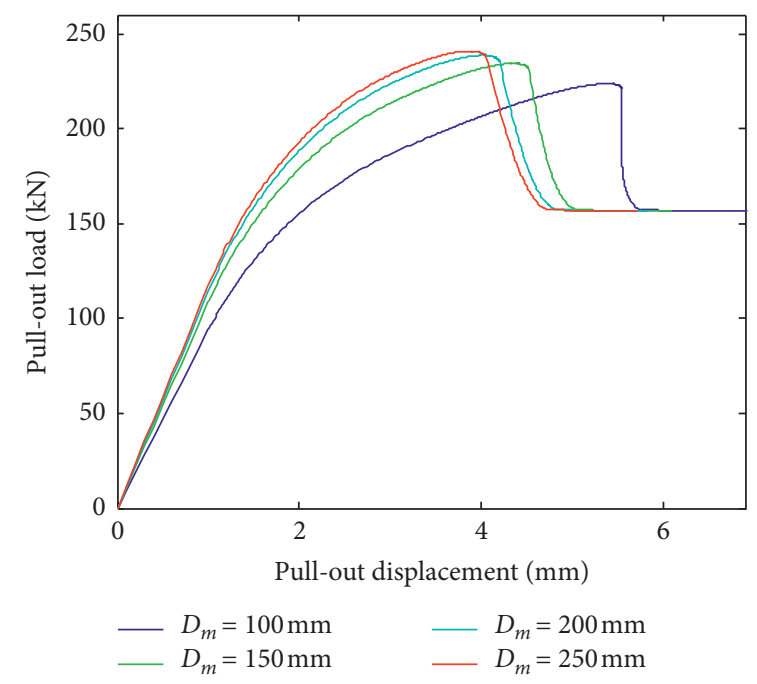

(b)

FIGURE 3: Rock bolt performance with different confining medium diameters: (a) bolting system geometry; (b) force-displacement relationship of rock bolts.

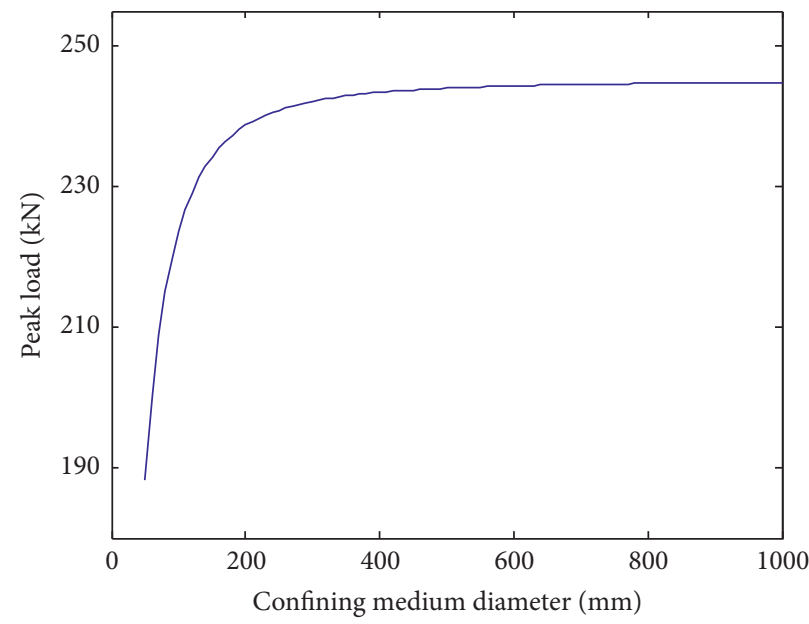

FIgURE 4: Peak force variation trend when the confining medium diameter was ascending.

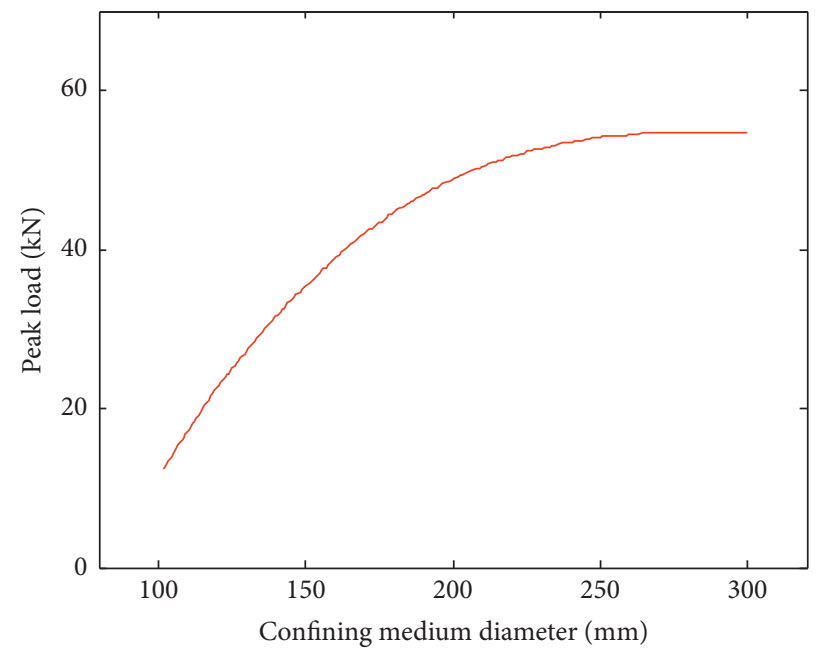

FIgure 5: Peak force variation trend of the plain cable bolts [18]. 


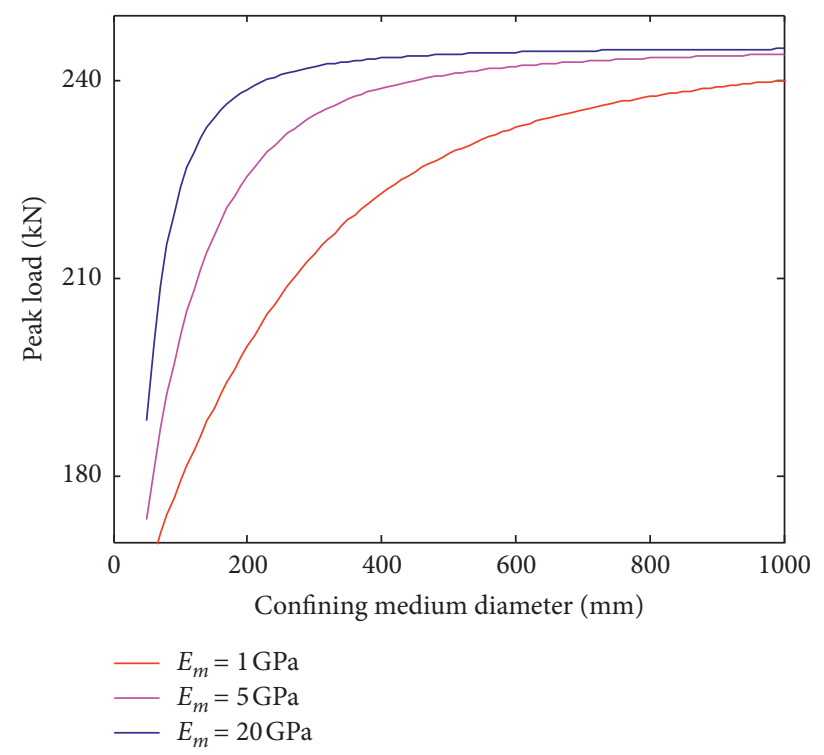

FIGURE 6: Peak force variation trend with the confining medium ascending when the confining medium modulus was under different levels.

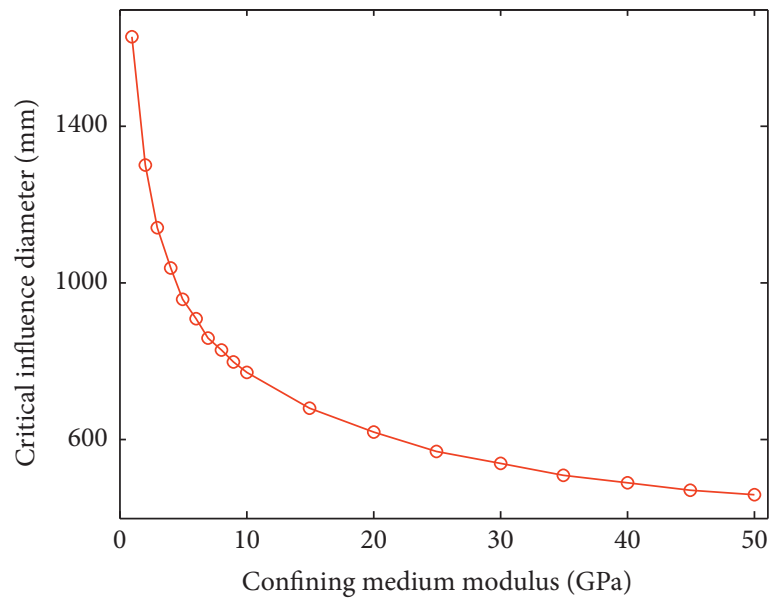

FIGURE 7: CID variation when the confining medium modulus was varying.

confining medium with a modulus of $1 \mathrm{GPa}$ was used. For it, at a diameter of $400 \mathrm{~mm}$, the peak force was still ascending rapidly.

To study the influence of the confining medium modulus on the CID, further pulling tests were performed. Specifically, the confining medium modulus was ranged from $1 \mathrm{GPa}$ to $50 \mathrm{GPa}$. With a certain confining medium modulus, the peak force variation trend was first computed. Then, the CID for that confining medium modulus was recorded. The CID was determined with the following method.

First, a relative difference percentage was defined:

$$
\Delta=\frac{F_{\max 2}-F_{\max 1}}{F_{\max 1}},
$$

where $\Delta$ is the relative difference percentage, $F_{\max 1}$ is peak force when the confining medium diameter was $a$, and $F_{\max 2}$ is peak force when the confining medium diameter was $(a+\Delta a)$.

In this paper, the confining medium diameter ascended with a small interval of $10 \mathrm{~mm}$. Then, when the relative difference percentage was smaller than $0.01 \%$, it was assumed that there was no apparent ascending of the peak force. Therefore, the corresponding confining medium diameter was regarded as the CID.

Following this method, the CID for different confining medium moduli was acquired, as shown in Figure 7. It can be seen that the confining medium modulus had a significant effect in determining the CID. With the confining medium modulus ascending, the CID declined nonlinearly. This indicated that, for the same rock bolt, if the confining medium properties were different, the corresponding CID may be different. Furthermore, the larger the confining medium modulus, the smaller the CID. 


\section{Conclusions}

Laboratory pulling tests were commonly used to study the performance of rock bolts. In pulling tests, natural or artificial cylindrical confining medium was usually used to confine rock bolts. This paper conducted an analytical investigation to study the influence of the confining medium diameter on the performance of rock bolts. In the analytical modelling, the load-carrying capacity of rock bolts with different confining medium diameters was compared. The results showed that the confining medium diameter had an apparent effect in determining the peak force of rock bolts. With the confining medium diameter ascending, the peak force ascended. However, the ascending rate of the peak force gradually declined. The peak force variation trend was compared with experimental results. And there was a good agreement between modelling trend and experimental trend.

The rock bolt peak force with different confining medium moduli was studied. It was found that although the confining medium modulus was different, the peak force variation trend was consistent. For each medium modulus, there was a certain CID. Beyond that CID, further ascending, the confining medium diameter had marginal effect in improving the peak force of rock bolts.

Moreover, the influence of the confining medium modulus on the CID was analysed. The results showed that the higher the confining medium modulus, the smaller the CID.

\section{Data Availability}

The data are included within the article.

\section{Conflicts of Interest}

The authors declare no conflicts of interest.

\section{Acknowledgments}

This study was supported by National Natural Science Foundation of China (51904302, 51774112, and 52034009) and Fundamental Research Funds for the Central Universities (2021YQNY05).

\section{References}

[1] D. Li, Y. Li, and W. Zhu, "Analytical modelling of loaddisplacement performance of cable bolts incorporating cracking propagation," Rock Mechanics and Rock Engineering, vol. 53, no. 8, pp. 3471-3483, 2020.

[2] A. Batugin, Z. Wang, Z. Su, and S. S. Sidikovna, "Combined support mechanism of rock bolts and anchor cables for adjacent roadways in the external staggered split-level panel layout," International Journal of Coal Science and Technology, vol. 2021, pp. 1-15, 2021.

[3] A. G. Thompson, E. Villaescusa, and C. R. Windsor, "Ground support terminology and classification: an update," Geotechnical and Geological Engineering, vol. 30, no. 3, pp. 553580, 2012.
[4] S. Nakamoto, N. Iwasa, and J. Takemura, "Effects of nails and facing plates on seismic slope response and failure," Géotechnique Letters, vol. 7, no. 2, pp. 136-145, 2017.

[5] K. Skrzypkowski, W. Korzeniowski, K. Zagórski, and A. Zagórska, "Modified rock bolt support for mining method with controlled roof bending," Energies, vol. 13, pp. 1-20, 2020.

[6] G. Liu, M. Xiao, J. Chen, and H. Zhou, "Study on mechanical characteristics of fully grouted rock bolts for underground caverns under seismic loads," Mathematical Problems in Engineering, vol. 2017, pp. 1-12, 2017.

[7] J. Chen, H. Zhao, F. He, J. Zhang, and K. Tao, "Studying the performance of fully encapsulated rock bolts with modified structural elements," International Journal of Coal Science and Technology, vol. 8, no. 1, pp. 1-13, 2021.

[8] S. Wang, D. Li, C. Li, C. Zhang, and Y. Zhang, "Thermal radiation characteristics of stress evolution of a circular tunnel excavation under different confining pressures," Tunnelling and Underground Space Technology, vol. 78, pp. 76-83, 2018.

[9] S. Wang, X. G. Wu, J. H. Yang, J. Q. Zhao, and F. L. Kong, "Mechanical behavior of lightweight concrete structures subjected to 3D coupled static-dynamic loads," Acta Mechanica, vol. 231, 2020.

[10] D. Li, H. Masoumi, S. Saydam, and P. C. Hagan, "Mechanical characterisation of modified cable bolts under axial loading: an extensive parametric study," Rock Mechanics and Rock Engineering, vol. 51, no. 9, pp. 2895-2910, 2018.

[11] K. Skrzypkowski, W. Korzeniowski, K. Zagórski, and A. Zagórska, "Flexibility and load-bearing capacity of roof bolting as functions of mounting depth and hole diameter," Energies, vol. 12, pp. 1-23, 2019.

[12] D. Li, H. Masoumi, P. C. Hagan, and S. Saydam, "Experimental and analytical study on the mechanical behaviour of cable bolts subjected to axial loading and constant normal stiffness," International Journal of Rock Mechanics and Mining Sciences, vol. 113, pp. 83-91, 2019.

[13] S. Ma, X. Zhu, W. Qin, and S. Hu, "Determination of the bond-slip relationship of fully grouted rockbolts," Environmental Earth Sciences, vol. 77, no. 9, pp. 325-326, 2018.

[14] L. Blanco Martín, M. Tijani, F. Hadj-Hassen, and A. Noiret, "Assessment of the bolt-grout interface behaviour of fully grouted rockbolts from laboratory experiments under axial loads," International Journal of Rock Mechanics and Mining Sciences, vol. 63, pp. 50-61, 2013.

[15] Q. He, Y. Li, J. Xu, and C. Zhang, "Prediction of mechanical properties of igneous rocks under combined compression and shear loading through statistical analysis," Rock Mechanics and Rock Engineering, vol. 53, 2020.

[16] C. C. Li, "Performance of D-bolts under static loading," Rock Mechanics and Rock Engineering, vol. 45, no. 2, pp. 183-192, 2012.

[17] Q. Meng, L. Han, J. Sun, F. Min, W. Feng, and X. Zhou, "Experimental study on the bolt-cable combined supporting technology for the extraction roadways in weakly cemented strata," International Journal of Mining Science and Technology, vol. 25, no. 1, pp. 113-119, 2015.

[18] H. Rajaie, Experimental and Numerical Investigations of Cable Bolt Support Systems, McGill University, Montreal, Canada, 1990.

[19] J. Chen, P. C. Hagan, and S. Saydam, "Sample diameter effect on bonding capacity of fully grouted cable bolts," Tunnelling and Underground Space Technology, vol. 68, pp. 238-243, 2017. 
[20] W. Zhang, L. Huang, and C. H. Juang, "An analytical model for estimating the force and displacement of fully grouted rock bolts," Computers and Geotechnics, vol. 117, pp. 1-10, 2020.

[21] J. Zou and P. Zhang, "Analytical model of fully grouted bolts in pull-out tests and in situ rock masses," International Journal of Rock Mechanics and Mining Sciences, vol. 113, pp. 278-294, 2019.

[22] H.-C. Ma, X.-H. Tan, J.-Z. Qian, and X.-L. Hou, "Theoretical analysis of anchorage mechanism for rock bolt including local stripping bolt," International Journal of Rock Mechanics and Mining Sciences, vol. 122, pp. 1-6, 2019.

[23] D. Li, H. Masoumi, S. Saydam, and P. C. Hagan, "A constitutive model for load-displacement performance of modified cable bolts," Tunnelling and Underground Space Technology, vol. 68, pp. 95-105, 2017.

[24] S. Ma, J. Nemcik, N. Aziz, and Z. Zhang, "Analytical model for rock bolts reaching free end slip," Construction and Building Materials, vol. 57, pp. 30-37, 2014.

[25] J. Chen, S. Yang, H. Zhao, J. Zhang, F. He, and S. Yin, "The analytical approach to evaluate the load-displacement relationship of rock bolts," Advances in Civil Engineering, vol. 2019, pp. 1-15, 2019.

[26] S. Ma, Z. Zhao, W. Nie, and Y. Gui, "A numerical model of fully grouted bolts considering the tri-linear shear bond-slip model," Tunnelling and Underground Space Technology, vol. 54, pp. 73-80, 2016.

[27] F. F. Ren, Z. J. Yang, J. F. Chen, and W. W. Chen, "An analytical analysis of the full-range behaviour of grouted rockbolts based on a tri-linear bond-slip model," Construction and Building Materials, vol. 24, no. 3, pp. 361-370, 2010.

[28] C. Cao, T. Ren, C. Cook, and Y. Cao, "Analytical approach in optimising selection of rebar bolts in preventing rock bolting failure," International Journal of Rock Mechanics and Mining Sciences, vol. 72, pp. 16-25, 2014.

[29] C. Cao, J. Nemcik, N. Aziz, and T. Ren, "Analytical study of steel bolt profile and its influence on bolt load transfer," International Journal of Rock Mechanics and Mining Sciences, vol. 60, pp. 188-195, 2013.

[30] S. Ma, J. Nemcik, and N. Aziz, "An analytical model of fully grouted rock bolts subjected to tensile load," Construction and Building Materials, vol. 49, pp. 519-526, 2013.

[31] N. Vlachopoulos, D. Cruz, and B. Forbes, "Utilizing a novel fiber optic technology to capture the axial responses of fully grouted rock bolts," Journal of Rock Mechanics and Geotechnical Engineering, vol. 10, no. 2, pp. 222-235, 2018. 